\title{
Study of psychiatric disorders among nepalese patients working abroad and their family members
}

\author{
B. Yengkokpam ${ }^{1}$, S. K. Shah ${ }^{2}$, G. R. Bhantana ${ }^{2}$ \\ ${ }^{1}$ Assistant Professor, ${ }^{2}$ Lecturer, Department of Psychiatry, College of Medical Sciences, Bharatpur, Nepal
}

\begin{abstract}
This study was carried out among the patients working abroad and their family members, having various psychiatric disorders. 80 patients attending psychiatry OPD between the age of 15 to 65 years both male and female in the period of July 2009 to July 2010 were included. The results were tabulated as per the diagnostic criteria of International Classification of Diseases (ICD-10). Out of total 80 patients, 41 were males and 39 were females, whose husbands were working abroad. 30 cases were of depression,out of which 16 were males and 14 were females. 18 cases were having anxiety disorders out of which 5 were males and 13 were females. 12 cases were suffering from psychotic disorders out of which 10 were males and 2 were females. 7 cases were having dissociative disorders with 1 male and 6 females. 4 cases were having somatoform disorders with 2 males and 2 females. 1 male and 1 female were suffering from mania. 1 male and 1 female were suffering from bipolar affective disorder. 2 males were alcohol dependent and 2 males were having obsessive compulsive disorder. 1 male was having organic psychosis.
\end{abstract}

Key words: Somatoform disorder, dissociative disorder, psychosis, organic psychosis, bipolar affective disorder.

\section{Introduction}

Nepal, a small country with an area of 147,000 square kilometers, has a total population of 23 million, according to a census carried out in 2001 by the Central Bureau of Statistics (CBS) and the current estimation is about 27 million. It is one of the poorest countries in the world with per capita GDP of about US $\$ 470{ }^{1}$ and it is estimated that about four in ten people live below the poverty line. It is a mountainous country situated on the lap of Himalayan range facing south towards the Plain of Ganges River.

Correspondence: B.Yengkokpam

E-mail: babkokpam@yahoo.com
Agriculture remains a major source of livelihood where about 85 percent of the population depend on agriculture. Commercialization of agriculture is not so common. Tourism is also popular due to its massive diversity in topography, altitude, climate, vegetation, people and culture. Poverty, unemployment, declining natural resources and country's experience of over a decade long political instability are some of the main causes of the high rate of migration. Despite the fact that many social, cultural, economic and political problems are interwoven with the process of both internal and international migration. $^{2}$ 
B. Yengkokpam et al, Study of psychiatric disorders of patients working outside Nepal

of 31-46 years, there were 22 cases in which 10 were males and 12 were females and in the third age group of 47-65 years, there were 3 cases in which 2 were males and 1 was female.

In disorder wise distribution, 18 were of anxiety disorders, 5 males and 13 females, maximum 30 cases were of depression with 16 males and 14 females. 4 were of somatoform disorder with 2 each of both male and female. 7 were of dissociative disorder with 1 male and 6 females. 2 cases were of mania with 1 each of both male and female. 12 cases were having psychosis with 10 males and 2 females. Only 1 case was of organic psychosis of 1 male. 2 cases were of alcohol dependent syndrome of 2 males. 2 cases were of bipolar affective disorder with 1 each of both male and female and 2 cases were of obsessive compulsive disorder of 2 males.

In the job wise distribution, among 41 males, 12 were army, 8 were technician, 11 were salesman, 10 were laborers and remaining 39 females were housewives. The difference between age range and sex was not found to be statistically significant but in case of age and marital status it was found to be statistically significant at 0.05 levels $\left(x^{2}=5.8439\right.$, $\mathrm{P}<0.05)$ and again in case of psychiatric disorders and sex it was found to be statistically significant at 0.01 levels $\left(\mathrm{x}^{2}=83.46, \mathrm{P}<0.01\right)$.

Table- 1: Age and sex of the patients included in the study

\begin{tabular}{|c|c|c|c|c|c|c|}
\hline $\begin{array}{l}\text { AGE } \\
\text { RANGE } \\
\text { in years }\end{array}$ & MALE & FEMALE & TOTAL & $\begin{array}{c}\text { df } \\
\text { (Degree } \\
\text { of freedom) }\end{array}$ & $\begin{array}{c}\chi^{2} \\
\text { (Chi } \\
\text { square) }\end{array}$ & $\begin{array}{c}\text { Level } \\
\text { of } \\
\text { significance } \\
\end{array}$ \\
\hline $15-30$ & 29 & 26 & 55 & & & \\
\hline $31-46$ & 10 & 12 & 22 & & & \\
\hline $47-65$ & 2 & 1 & 3 & 2 & 1.2698 & NS \\
\hline TOTAL & 41 & 39 & 80 & & & \\
\hline
\end{tabular}

Table- 2: Marital status of patients included in the study

\begin{tabular}{lcccccc}
\hline $\begin{array}{l}\text { AGE } \\
\text { RANGE } \\
\text { in years }\end{array}$ & MARRIED & UNMARRIED & TOTAL & df & $\chi^{2}$ & $\begin{array}{c}\text { Level } \\
\text { of } \\
\text { significance }\end{array}$ \\
\hline $15-30$ & 34 & 21 & 55 & & & \\
$31-46$ & 19 & 3 & 22 & 2 & 5.8439 & 0.05 \\
$47-65$ & 3 & 0 & 3 & & \\
\hline TOTAL & $\mathbf{5 6}$ & $\mathbf{2 4}$ & $\mathbf{8 0}$ & & \\
\hline
\end{tabular}


B. Yengkokpam et al, Study of psychiatric disorders of patients working outside Nepal

In our study, 56 cases were married and remaining 24 were unmarried and maximum 55 of them were between the age of 15-30 years. The finding is consistent with the findings of Chandra B et al, in which 75 percent was found to be married (65 percent married and 10 percent widowed, separated or divorced) indicating the majority of migrants were married. Only 25 percent were found to be unmarried contradicting the popular myth that young women migrate to foreign countries for fun. ${ }^{11}$

Migrant women were found to migrate for work as early as at the age of 12 years and to the age of 50 years, but the majority 70 percent was found between 21 to 35 years of age. As stated above, the majority were found to be married and mothers of small children. Therefore, it is no surprise that for many returnee migrants the saddest memory of their migration days was missing their children.

In disorder wise distribution, 18 were of anxiety disorders, maximum 30 cases were of depression, 4 of were somatoform disorder, 7 were having dissociative disorder with maximum 6 cases were females, 2 cases were of mania, 12 cases were of psychosis, only 1 case was having organic psychosis, 2 cases were of alcohol dependent syndrome, 2 cases were of bipolar affective disorder and 2 cases were of obsessive compulsive disorder.

It is obvious that male labour out-migration increases the female population in the community, which also leads to the increase of female headed households. However, in the context of Nepalese social structure the female household heads would have a de facto position with a limited decisionmaking power.
This finding is also supported by Kaspar in which their husbands have a major role in decisionmaking for strategic decisions, even if they are far away from home. However, they use this position in an ambiguous way, not only in deciding for which decisions they need their husband's consultation which increases stress and anxiety. Children are sent to private schools which are functioning better than the government schools in Nepal and mothers have worries and complain about their hardship to handle children in the absence of fathers. ${ }^{12}$

The labour out-migration has both positive and negative consequences for their elderly parents and children. On one hand, parents can be benefited from remittances or derive pride from their child's occupational or social success in the new setting. On the other hand, departure of a young and able bodied child could reduce availability to provide routine personal care or household help which lead to depression. ${ }^{13}$

A migrant worker has to face numerous problems while they make decision to migrate for foreign employment. A migrant takes a blind decision to migrate for work without any consideration of actual income, nature of the work and working environment that they receive in the country of destination. As a result, there are numerous realistic stories of the suffering of various psychiatric illnesses including psychosis among Nepalese migrant workers abroad. Numerous cases of intolerable sufferings of Nepalese migrant workers have been found abroad.

The large number of Nepalese worked illegally. Nepalese reach their destination countries after 